Lymphology 52 (2019) 71-81

\title{
INCREASED TRAFFICKING OF MIESENTERIC LYMIPH-DERIVED $\gamma \delta$ T CELLS INTO INTESTINAL MUCOSA IS ASSOCIATED WITH GUT INJURY AFTER INTESTINAL ISCHEMIA-REPERFUSION IN RATS
}

\author{
J. Yang, Y. Shen, R.Q. Wu, H. Zhu, Y. Jin, H. Yang
}

State Key Laboratory of Trauma, Burn and Combined Injury (JY), Army Medical University, Chongqing. Department of Pediatric Anesthesiology (JY), Children's Hospital of Nanjing Medical University, Nanjing. Department of Pediatric Gastroenterology (YS,RQW,HZ,YJ,HY), Children's Hospital of Nanjing Medical University, Nanjing, People's Republic of China

\section{ABSTRACT}

We sought to investigate the effects of mesenteric lymph-derived $\gamma \delta$ T cells trafficking into intestinal mucosa on gut injury after intestinal ischemia-reperfusion (IIR). $\gamma \delta T$ cells were separated from mesenteric lymph and then infused into the femoral vein of rats after the $\gamma \delta T$ cells were labeled with ${ }^{51} \mathrm{Cr}$. Migration of $\gamma \delta \mathrm{T}$ cells in vivo across the intestinal mucosa was determined by $\gamma$-counter. Meanwhile, TNF- $\alpha$ activity and endotoxin concentration in mesenteric lymph were detected. The population of $\gamma \delta$ T cells of Peyer's patches in the small intestines was analyzed by immunofluorescence double staining methods and flow cytometry. After IIR injury, the mean optical density value (MOD) and population of $\gamma \delta$ T cells in Peyer's patches of the gut and migration of ${ }^{51} \mathrm{Cr}-\gamma \delta \mathrm{T}$ cells across the intestinal mucosa were significantly increased, which had highly positive correlations to degree of intestinal injury, TNF- $\alpha$ levels and endotoxin concentration in mesenteric lymph after reperfusion. The increased population of $\gamma \delta T$ cells derived from mesenteric lymph trafficking into the intestinal mucosa might promote the small intestinal injury after IIR.
Keywords: $\gamma \delta \mathrm{T}$ cells, mesenteric lymph, T cell trafficking, ischemia-reperfusion, gut injury

Intestinal ischemia-reperfusion (IIR) injury, one of the most serious and common events, occurs in various clinical settings, including trauma, infection, organ transplantation, acute mesenteric arterial occlusion and shock. IRR subsequently leads to severe damage in local tissues and distant organs and is associated with high mortality up to $60-80 \%$ (1-2). It is an intense local inflammation that is produced in the small intestine transiently deprived of blood flow during reperfusion (3-4). More complex mechanisms that trigger inflammation are involved in its development and amplification but have been only partially identified (5-7). T cells have been implicated in the pathogenesis of IIR (8-10). They accumulate in damaged areas of the small intestines and cause local injury in the setting of mesenteric artery occlusion followed by reperfusion, which suggests that $T$ cells amplify the inflammatory responses (9-12).

$\gamma \delta \mathrm{T}$ cells are non-conventional T lymphocytes which comprise $1-5 \%$ of the circulating $T$ cell compartment found in secondary lymphoid tissue and peripheral blood in mice and 
humans, and play crucial roles in innate and acquired immune responses (13-14). Specific subsets of $\gamma \delta$ T cells are abundantly distributed in epithelial tissues such as the gastrointestinal track, the epidermis of the skin and the reproductive track where they have pro-inflammatory and anti-inflammatory dual functions depending on the anatomic locations and the microenvironment (15-17). Even though a major role for $\gamma \delta \mathrm{T}$ cells has been described in host defense against pathogens and cancer, prior studies demonstrate further that $\gamma \delta \mathrm{T}$ cells rapidly proliferate, produce cytokines, and present high cytotoxic activities, regulating several physiopathological conditions in a non-redundant manner when they accumulate in sites of infection- and non-infection-associated types of inflammation $(13,18-20)$. Although our understanding of $\gamma \delta \mathrm{T}$ cell development, maturation, activation and effector function has increased in recent years, many aspects still remain unknown (21). In particular, the role of intestinal $\gamma \delta \mathrm{T}$ cell migration in intestinal mucosal injury after IIR is still unclear.

In this study, we observed the changes in $\gamma \delta \mathrm{T}$ cell trafficking into intestinal mucosa after IIR injury and analyzed the correlation between the number of $\gamma \delta$ T cells migrating across the intestinal mucosa and gut damage after the failure of gut function.

\section{METHODS}

\section{Animals}

Male SD rats were purchased from and maintained under specific pathogen-free (SPF) conditions in the experimental animal center of Nanjing Medical University. (Nanjing, China). The rats were supplied a standard chow until they reached the desired body weight $(250-300 \mathrm{~g})$. This experiment was divided into Part A ( $n=6$ in each subgroup, total 5 subgroups), Part B ( $\mathrm{n}=6$ in each subgroup, total 5 subgroups) and Part $C(n=6$ in each subgroup, total 5 subgroups). In each Part, thirty rats were randomly divided into the following five subgroups: Control group (Con); Shamoperation group (Sham); IIR-2h group (IIR 2h); IIR-4h group (IIR-4h) and IIR $6 \mathrm{~h}$ group (IIR 6h), six rats in each subgroup. In Part C, the number of rats available to provide each of the end-point measurements was reduced to four rats in each subgroup due to the failure of cannulation or insufficient number of lymphocytes collected from mesenteric lymph, while the final number of rats was unchanged in Part A and Part B. This study was approved by the Experimental Animal Review Board of Nanjing Medical University in Nanjing, China, and followed the national guidelines for the treatment of animals.

\section{IIR Procedure}

The rat model of IIR was established as previously described (22). The rats were fasted, but allowed free access to water, $12 \mathrm{~h}$ before the experiment. After induction of anaesthesia with amobarbital by intraperitoneal injection, a midline laparotomy was performed to expose the intestine. Then, the superior mesenteric artery (SMA) was isolated and blocked with a microvascular clamp to achieve complete ischemia for $45 \mathrm{~min}$. Upon release of the clamp, the rats were allowed to recover from anesthesia for $2 \mathrm{~h}, 4 \mathrm{~h}$ and $6 \mathrm{~h}$. After the reperfusion, the rats were sacrificed and the small intestines were removed. The rats in the control group received no additional treatment. In the sham-operation group, the SMA was isolated without clamping and was exposed to the same procedure as rats with SMA occlusion.

\section{Immunofluorescent Staining}

Peyer's patches were separated from the small intestines. Samples were frozen and cut into 5 - $\mu \mathrm{m}$ sections, which were then processed for immunofluorescent staining. After incubation with rabbit against rat CD3 and $\gamma \delta$ TCR antibodies (Abcam Co, UK), followed by FITC or cy3-conjugated goat anti-rabbit IgG treated separately (Jackson ImmunoResearch Co, USA), images were acquired with a confocal 
microscope (Zeiss LSM 710, Germany). The mean optical density value (MOD) of immunofluorescent staining $\gamma \delta$ T cells was analyzed using Image Pro Plus 6.0 software (Media Cybernetics Co, USA).

\section{Flow Cytometry}

Peyer's patches separated from the small intestines were broken in PBS and then the suspension was filtered through $\mathbf{1 0 0}$ micron nylon net and further centrifuged for $5 \mathrm{~min}$ at $1000 \mathrm{rpm}$ and the pellet collected and washed in PBS twice. For extracellular staining, cells were pre-incubated in a mixture of PBS, $2 \%$ fetal calf serum, and $0.1 \%$ (w/v) sodium azide with FcgIII/IIR-specific antibody to block nonspecific binding and stained with different combinations of fluorochrome-coupled CD3 $(0.5 \mathrm{mg} / \mathrm{ml})$ and $\gamma \delta \mathrm{TCR}(0.2 \mathrm{mg} / \mathrm{ml})$ antibodies (Abcam Co. UK). Simultaneously, rabbit against rat IgG1-PE/IgG2b-PE homotypic negative control antibody (Abcam Co. UK) was added into the negative control tubes. Cells were collected on a FACSCanto II system (BD Biosciences) and data were analyzed using FlowJo software (TreeStar Co. USA).

\section{Time Frame for Mesenteric Lymph Collection}

In Part C, mesenteric lymph was collected for one hour in the $1^{\text {st }}, 3^{\text {rd }}$, and $5^{\text {th }}$ hours, respectively, after reperfusion following occluding the SMA for $45 \mathrm{~min}$ in the IIR $2 \mathrm{~h}$, IIR $4 \mathrm{~h}$ or IIR $6 \mathrm{~h}$ groups. In the control and sham-operation groups, the SMA in rats was not clamped and mesenteric lymph was collected according to the same procedure as rats with SMA occlusion. After collection stopped, the lymphocytes were collected and $\gamma \delta$ T cells were separated. Then, the $\gamma \delta \mathrm{T}$ cells were labeled with ${ }^{51} \mathrm{Cr}$ and infused into the femoral veins of rats at the beginning of the $2^{\text {nd }}, 4^{\text {th }}$, and $6^{\text {th }}$ hours after reperfusion, $1 \mathrm{~h}$ later, the rats were killed. Peyer's patches and diffusive intestinal lymphoid tissues containing ${ }^{51} \mathrm{Cr}$ labeled $\gamma \delta$ T cells were removed and counted with a $\gamma$ - counter (TDC501, Aloka Co, Japan).

\section{Separation of $\gamma \delta$ T Cells}

The procedures used to collect the mesenteric lymphocytes in rats have been described previously (9). Briefly, the rats were anesthetized with amobarbital by intraperitoneal injection. A midline laparotomy was performed and the mesenteric lymphatic vessel identified (adjacent to the SMA) by reflecting the loops of intestine to the left of the animal with moist gauze swabs. A plastic tube, $1 \mathrm{~mm}$ in diameter, with beveled ends, was passed into the mesenteric lymphatic and lymph flow began immediately through the tube. Mesenteric lymph was centrifuged for $5 \mathrm{~min}$ at $1000 \mathrm{rpm}$ and lymphocytes were collected and washed in PBS twice. Lymphocytes were labeled with $\gamma \delta$ TCR microbeads (Miltenyi Biotec, Germany) and separated by magnetic activated cell sorting (MACS) following the manufacturer's instruction. Cell viability was determined by $0.2 \%$ Evans blue staining. More than $95 \%$ of the cells were viable for measurement of $\gamma \delta \mathrm{T}$ cell subsets. $\gamma \delta \mathrm{T}$ cell subsets were analyed by flow cytometry.

\section{Detection of ${ }^{51} \mathrm{Cr}$ Labeled $\gamma \delta$ T Cell Migration}

The procedures used to label lymphocytes with ${ }^{51} \mathrm{Cr}$ have been described previously (22). Briefly, $1 \times 10^{6} \gamma \delta \mathrm{T}$ cells $/ \mathrm{ml}$ in RPMI 1640 (containing 20\% fetal bovine serum) was incubated with $20 \mu \mathrm{Ci} / \mathrm{ml} \mathrm{Na}_{2}\left[{ }^{51} \mathrm{Cr}\right] \mathrm{O}_{4}$ (Amersham Pharmacia Co, UK) for $1 \mathrm{~h}$ at $37^{\circ} \mathrm{C}$ in water. After incubation, the liquid was centrifuged at $500 \mathrm{~g}$ for 5 minutes, then the supernatant was decanted and the remainder was added into a test tube containing $100 \%$ fetal bovine serum and $17 \%$ Nycodenz (Sigma Co, USA). The liquid mix was centrifuged at $1200 \mathrm{~g}$ for 5 minutes. The ${ }^{51} \mathrm{Cr}$ labeled $\gamma \delta \mathrm{T}$ cells were collected from the layer between fetal bovine serum and Nycodenz. $5 \times 10^{5} \gamma \delta$ T cells labeled with ${ }^{51} \mathrm{Cr}$ mixed with $0.4 \mathrm{ml}$ RPMI-1640 was infused slowly into the femoral vein. $1 \mathrm{~h}$ later, rats were killed and the small intestines were removed. The Peyer's patches and diffusive intestinal lymphoid tissues containing ${ }^{51} \mathrm{Cr}$ 
labeled $\gamma \delta$ T cells were measured by a $\gamma$-counter (TDC-601, Aloka Co, Japan). The data were calculated as the percentage of organ containing labeled lymphocytes divided by the total quantity of labeled lymphocytes in vivo.

\section{TNF- $\alpha$ and Endotoxin in Mesenteric Lymph}

In Part A, mesenteric lymph was collected for one hour in the $2^{\text {nd }}, 4^{\text {th }}$, and $6^{\text {th }}$ hours, respectively, after reperfusion following occluding the SMA for $45 \mathrm{~min}$ in the IIR $2 \mathrm{~h}$, IIR $4 \mathrm{~h}$ or IIR $6 \mathrm{~h}$ groups. In the control and sham operation groups, the SMA in rats was not clamped and mesenteric lymph was collected according to the same procedure as rats with SMA occlusion. After collection stopped, mesenteric lymph was centrifuged at $500 \mathrm{~g}$ for $5 \mathrm{~min}$, and the supernatant was collected for the detection of TNF- $\alpha$ activity and endotoxin concentration. TNF- $\alpha$ activity was determined by using rat TNF-enzyme-linked immunoabsorbant assay (ELISA) kit (LIFEKEY Biotech, Co, USA) according to the manufacturer's protocol. Endotoxin concentration was assayed using the Limulus test kit (Yihua Clinical Technology Co, Shanghai, China). The assay depends on bacterial endotoxin to activate a proenzyme in the limulus amoebocyte lysate that catalyzes the cleavage of p-nitroanaline (pNA) from the colorless substrate. The pNA was assayed spectrophotometrically at $545 \mathrm{~nm}$ providing a quantitative analysis of endotoxin content.

\section{Intestinal Histology}

Specimens from the small intestine $(5 \mathrm{~cm}$ from the distal end of ileum) were removed and fixed with $10 \%$ formaldehyde. The paraffin sections were stained with hematoxylin and eosin for histological evaluation in a single blinded fashion. The degree of gut injury was evaluated according to the Park Chiu Scale (23): Grade 0: Normal mucosa; Grade 1: Subepithelial bleb at the tip of the villus; Grade 2: More extended subepithelial space (upper half of the villus); Grade 3: Epithelial lifting down to the base of the villus, occasional epithelial breakdown; Grade 4: Frequent denuded villi; Grade 5: Loss of villous tissue; Grade 6: Crypt layer destruction; Grade 7: Transmucosal infarction; Grade 8: Transmural infarction. For evaluation of lesions, $\mathbf{1 0}$ arbitrary microscopic fields were viewed in each sample.

\section{Statistical Analysis}

All quantitative data were presented as mean \pm SD and were analyzed using GraphPad Prism 5.0 (GraphPad Software, La Jolla, CA). Statistical analysis was performed by one-way analysis of variance (ANOVA). Difference was considered statistically significant at $\mathrm{P}<0.05$. Pearson correlation coefficient were calculated to assess correlation between Increased $\gamma \delta \mathrm{T}$ cell migration and degree of gut injury after IIR. Analysis was performed using IBM SPSS Statistics 21 software (IBM Corporation, USA). Difference was considered statistically significant when $\mathrm{P}<0.05$.

\section{RESULTS}

\section{Changes in gut histology after IIR}

As shown in Fig. 1, the villi structure of the control and the sham operation group was complete without obvious bleeding points, and the villi end and the lamina propria were not damaged. Sparse intestinal villi and structural damage, a congestion of mucosal blood vessels were visible in the IIR $2 \mathrm{~h}$ group. The lamina was destroyed, the villous tissue was damaged, the amount of bleeding increased in the IIR 4h group; The villus tissue structure was recovered and the villi tip was slightly separated from the lamina propria in the IIR $6 \mathrm{~h}$ group (Fig. 1). Park Chiu Scale for grading the inflammatory lesions of the distal end of the ileum after IIR injury were $3.00 \pm 1.00,6.67$ $\pm 0.58,3.33 \pm 1.53$, respectively, at the $2^{\text {nd }}, 4^{\text {th }}$, and $6^{\text {th }}$ hours after reperfusion, which were obviously higher than those in the control and sham operation groups $(\mathrm{P}<0.05)$. 

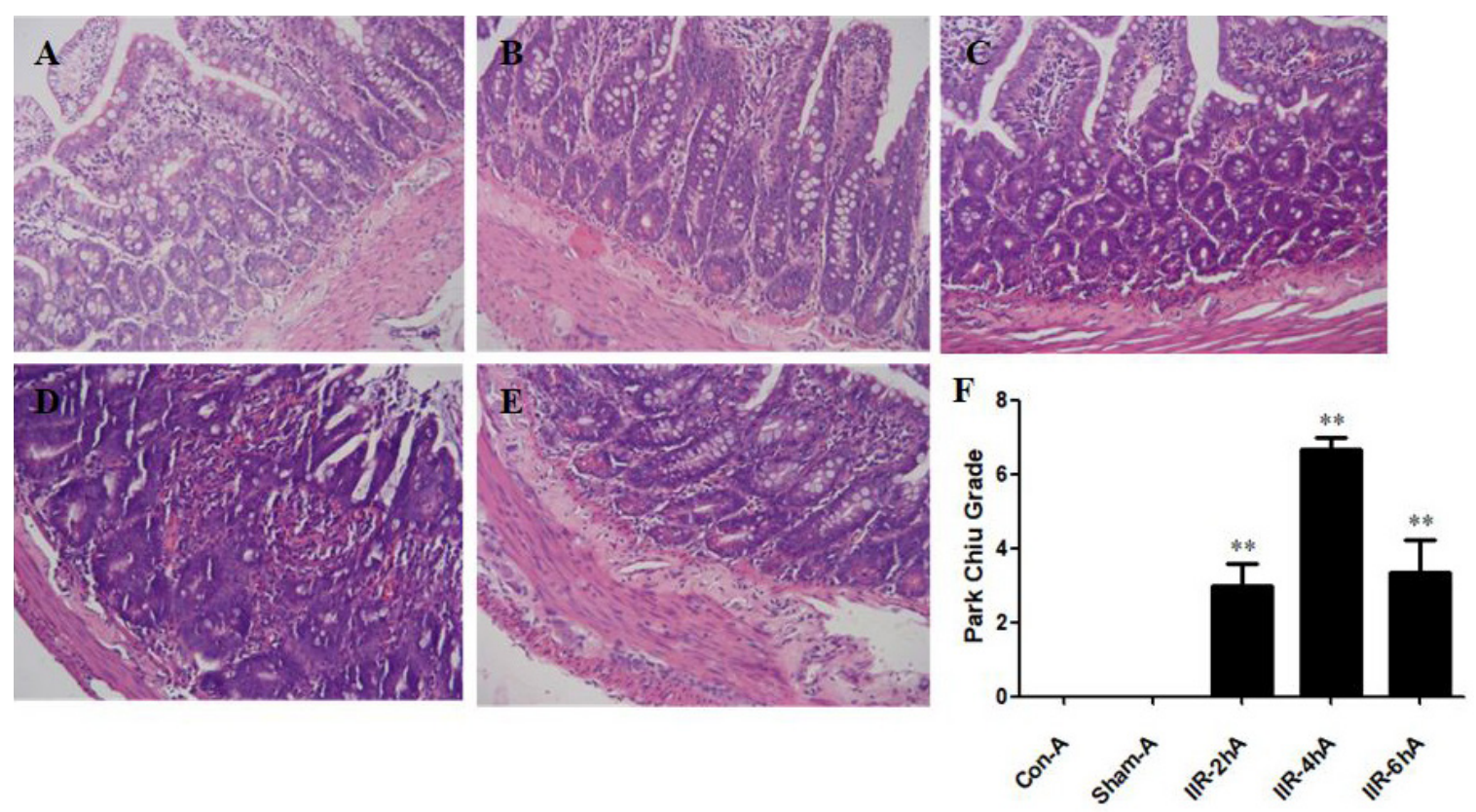

Fig. 1. Different degree of intestinal injury at different time points after intestinal isochemia-reperfusion (IIR) in rats. Representative histological sections of hematoxylin and eosin $(H \& E)$-stained intestinal tissues from $S D$ rats (×200). A. Control group, B. Sham-operation group, C-E. Gut injury induced by 45 min of SMA occlusion followed by $2 h(C), 4 h D)$ and $6 h(E)$ of reperfusion. $n=6$ in each group. F. Intestinal injury was assessed by using the Park Chiu Scale (Score: 0-8). ConA: Control, Sham-A: Sham-operation, IIR-2hA, 4hA and 6hA: at the $2^{\text {nd }}$, $4^{\text {th }}$, and $6^{\text {th }}$ hours after reperfusion. $* P<0.05, * * P<0.01$ compared with control group.

\section{Alterations in TNF- $\alpha$ and endotoxin in mesenteric lymph after IIR}

TNF- $\alpha$ levels in mesenteric lymph were $(65.73 \pm 3.86) \mathrm{g} / \mathrm{ml},(93.07 \pm 8.79) \rho \mathrm{g} / \mathrm{ml}$ and $(67.82 \pm 6.25) \rho g / m l$, respectively, at the $2^{\text {nd }}$, $4^{\text {th }}$, and the $6^{\text {th }}$ hours after occluding the SMA for $45 \mathrm{~min}$ followed by reperfusion. These levels were significantly increased $(\mathrm{P}<0.05$, Fig. 2A) compared with the control and shamoperation groups (TNF- $\alpha$ detection value in both groups was zero $\mathrm{g} / \mathrm{ml}$ ). Meanwhile, endotoxin levels in the above three groups were $(0.11 \pm 0.03) \mathrm{EU} / \mathrm{mL},(0.21 \pm 0.03) \mathrm{EU} /$ $\mathrm{mL}$, and $(0.12 \pm 0.02) \mathrm{EU} / \mathrm{mL}$, which were also higher than those in the control $([0.05 \pm 0.02]$ $\mathrm{EU} / \mathrm{mL})$ and sham-operation $([0.05 \pm 0.01]$ $\mathrm{EU} / \mathrm{mL})$ groups $(\mathrm{P}<0.05$, Fig. $2 B)$.

\section{Increased population of $\gamma \delta$ T cells in Peyer's patches after IIR}

Compared with the control and shamoperation group, population of $\gamma \delta \mathrm{T}$ cells in Peyer's patches of the gut at the $2^{\text {nd }}$ hour ([5.21 $\pm 0.16] \%$ vs $[2.88 \pm 0.24] \%$ or $[3.36 \pm 0.54] \%$, $\mathrm{p}<0.05)$, the $4^{\text {th }}$ hour $([5.66 \pm 0.33] \%$ vs $[2.88$ $\pm 0.24] \%$ or $[3.36 \pm 0.54] \%, \mathrm{p}<0.05)$ and the $6^{\text {th }}$ hour $([5.25 \pm 0.22] \%$ vs $[2.88 \pm 0.24] \%$ or $[3.36 \pm 0.54] \%, \mathrm{p}<0.05)$ after IIR was significantly increased (Fig. 3).

Increased MOD of $\gamma \delta$ T cells staining in Peyer's patches after IIR

Compared with the control and sham operation group, the mean optical density value 

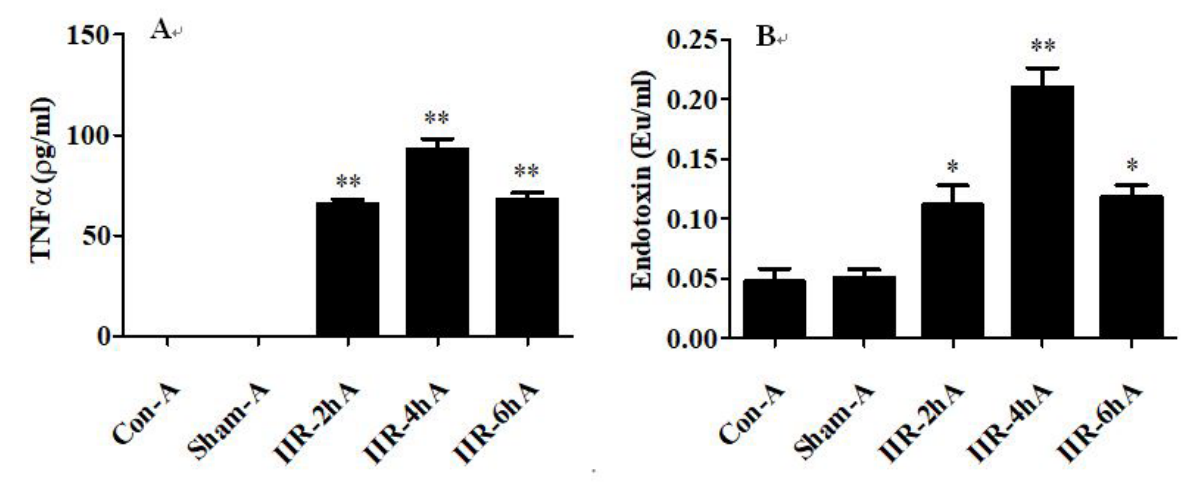

Fig. 2. Different alteration of TNF- $\alpha(A)$ and endotoxin (B) levels in mesenteric lymph at the different time points after intestinal isochemia-reperfusion (IIR) in rats. IIR injury was induced by 45 min of SMA occlusion, followed by $2 \mathrm{~h}$, $4 \mathrm{~h}$ and $6 \mathrm{~h}$ of reperfusion. $n=6$ in each group. ConA: Control, Sham-A: Sham-operation, IIR-2hA, 4hA and 6hA: at the $2^{\text {nd }}, 4^{\text {th }}$, and $6^{\text {th }}$ hours after reperfusion. $* P<0.05, * * P<0.01$ compared with control group.
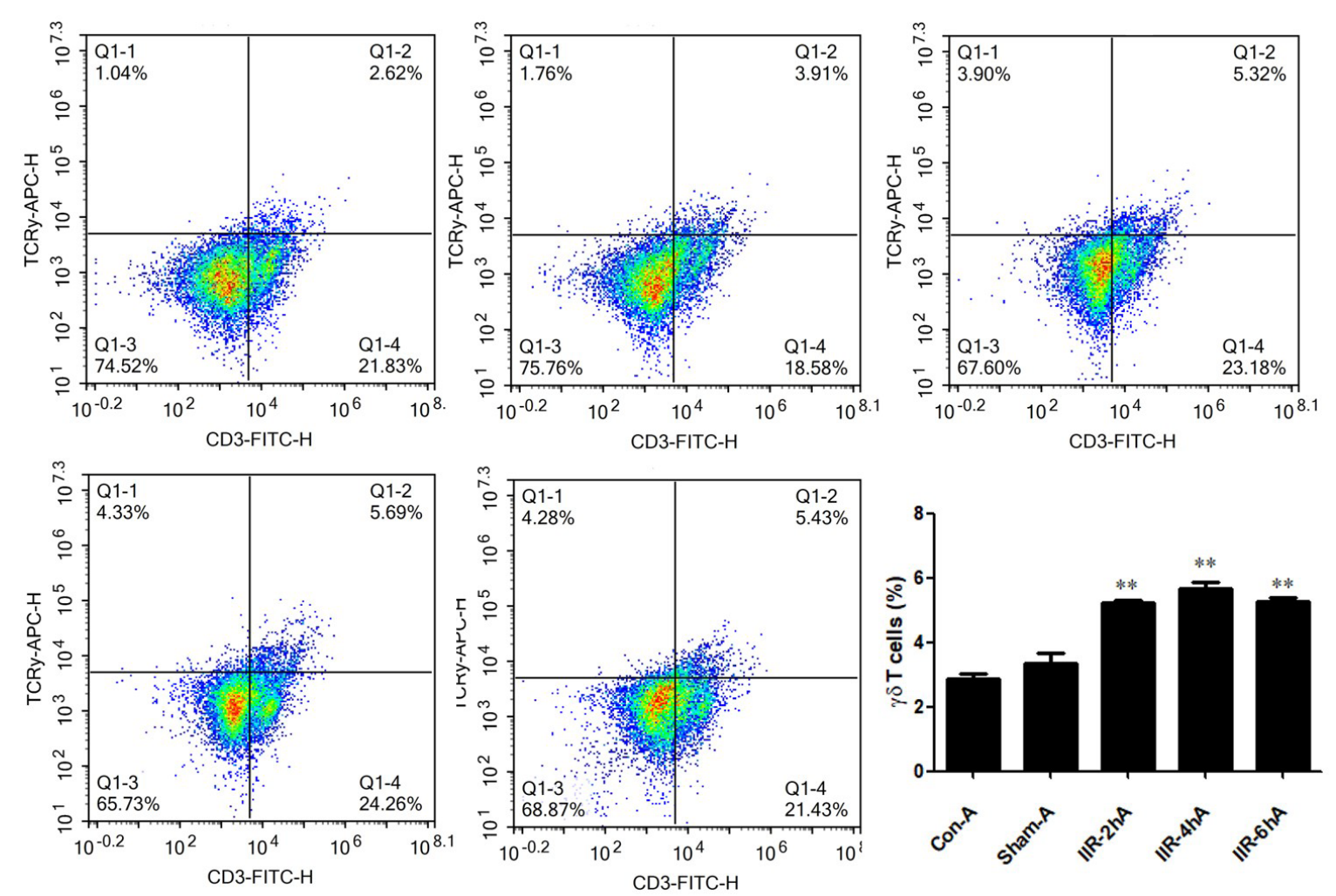

Fig. 3. Changes of population of $\gamma \delta T$ cells in Peyer's patches in the gut at the different time points after intestinal isochemia-reperfusion (IIR) in rats. $\gamma \delta T$ cells were stained with fluorochrome-coupled CD3 and $\gamma \delta T C R$ antibodies and measured by flow cytometry. A. Control group, B. Sham-operation group, C-E. Gut injury induced by 45 min of $S M A$ occlusion followed by $2 h(C), 4 h D)$ and $6 h(E)$ of reperfusion. $n=3$ in each group. $F$. The population of $\gamma \delta T$ cells in each group. ConA: Control, Sham-A: Sham-operation, IIR-2hA, 4hA and 6hA: at the $2^{\text {nd }}, 4^{\text {th }}$, and $6^{\text {th }}$ hours after reperfusion. $* P<0.05, * * P<0.01$ compared with control group. 

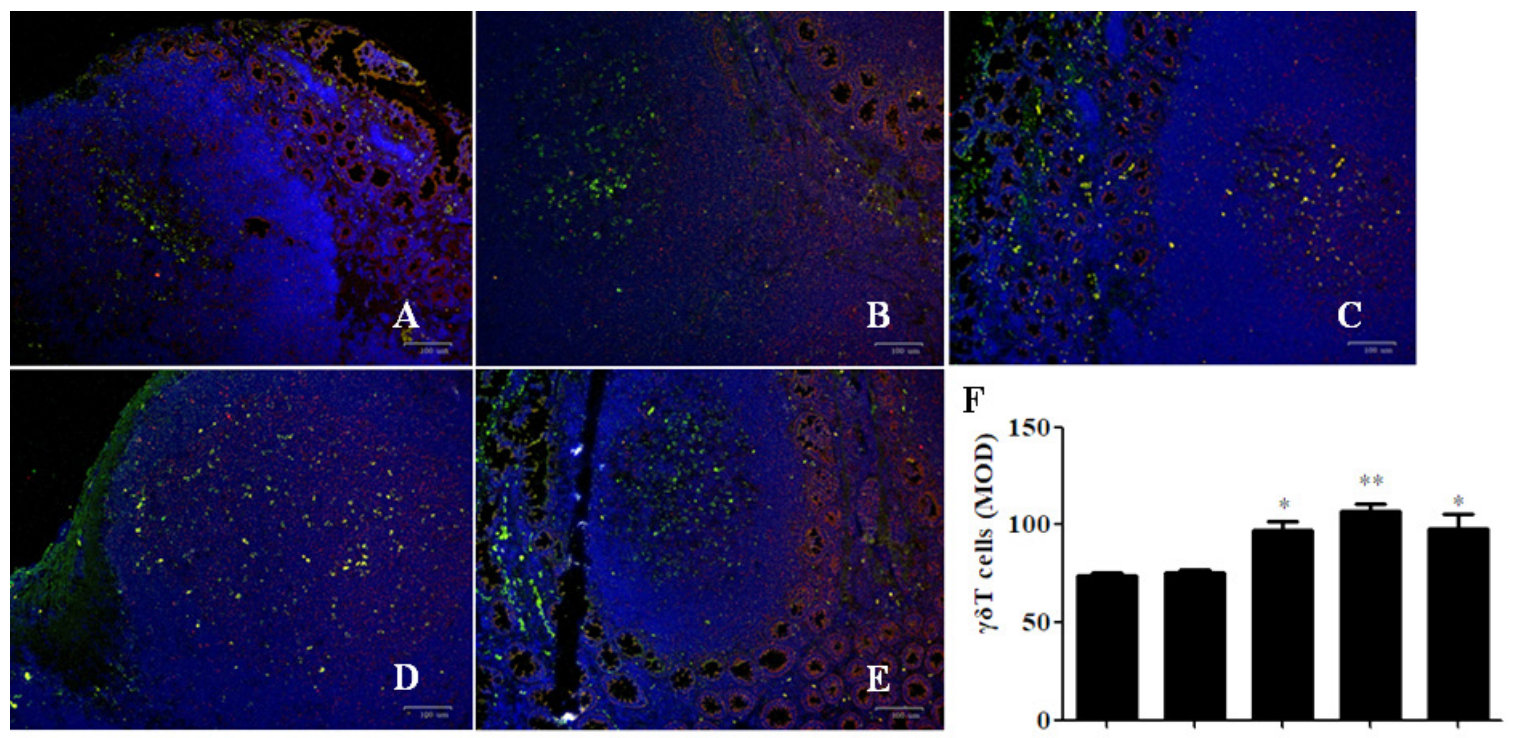

Fig. 4. Changes of the mean optical density value (MOD) of $\gamma \delta T$ cells staining in Peyer' patches at the different time points after intestinal isochemia-reperfusion (IIR) in rats. $\gamma \delta T$ cells were observed by immunofluorescent staining (yellow, merged; red, CD3 staining; green, $\gamma \delta T C R$ staining; DAPI nuclear staining; $\times 100)$. A. Control group, B. Sham-operation group, $C$-E. Gut injury induced by 45 min of SMA occlusion followed by $2 h(C), 4 h D)$ and $6 h(E)$ of reperfusion. $n=6$ in each group. $F$. The MOD of $\gamma \delta T$ cells in each group. Con-B: Control, Sham-B: Sham-operation, IIR-2hB, $4 \mathrm{hB}$ and $6 \mathrm{hB}:$ at the $2^{\text {nd }}, 4^{\text {th }}$, and $6^{\text {th }}$ hours after reperfusion. $* P<0.05, * * P<0.01$ compared with control group.

(MOD) of $\gamma \delta \mathrm{T}$ cells staining in Peyer's patches of the gut at the 2 nd hour $([96.96 \pm 7.25] \%$ vs $[74.01 \pm 2.11] \%$ or $[75.19 \pm 3.72] \%, \mathrm{P}<0.05)$, the 4th hour $([106.80 \pm 0.33] \%$ vs $[74.01 \pm 2.11]$ $\%$ or $[75.19 \pm 3.72] \%, \mathrm{P}<0.05)$ and the 6 th hour $([98.23 \pm 13.18] \%$ vs $[74.01 \pm 2.11] \%$ or $[75.19 \pm 3.72] \%, P<0.05)$ after IIR injury was significantly increased (Fig .4).

Increased ${ }^{51} \mathrm{Cr}-\gamma \delta \mathrm{T}$ cells migration across intestinal mucosa after IIR

Compared with the control and shamoperation group, population of ${ }^{51} \mathrm{Cr} \gamma \delta \mathrm{T}$ cell trafficking into Peyer's patches at the $2^{\text {nd }}$ hour $([0.95 \pm 0.15] \%$ vs $[0.58 \pm 0.16] \%$ or $[0.59 \pm$ $0.15] \%, P<0.05)$, the $4^{\text {th }}$ hour $([1.70 \pm 0.13] \%$ vs $[0.58 \pm 0.16] \%$ or $[0.59 \pm 0.15] \%, \mathrm{P}<0.05)$ and the $6^{\text {th }}$ hour $([0.96 \pm 0.12] \%$ vs $[0.58 \pm$
$0.16] \%$ or $[0.59 \pm 0.15] \%, \mathrm{P}<0.05)$ after reperfusion and into diffusive intestinal lymphoid tissues (excluding Peyer's patches) at the $2^{\text {nd }}$ hour $([0.57 \pm 0.04] \%$ vs $[0.29 \pm 0.08] \%$ or $[0.29 \pm 0.07] \%, \mathrm{P}<0.05)$, the $4^{\text {th }}$ hour $([1.02 \pm$ $0.08] \%$ vs $[0.29 \pm 0.08] \%$ or $[0.29 \pm 0.07] \%$, $\mathrm{P}<0.05)$ and the $6^{\text {th }}$ hour $([0.58 \pm 0.07] \%$ vs $[0.29 \pm 0.08] \%$ or $[0.29 \pm 0.07] \%, P<0.05$ ) after reperfusion were significantly increased (Fig. 5).

\section{Increased $\gamma \delta$ T cell migration correlates with degree of gut injury after IIR}

Pearson correlation coefficient analysis indicated that the MOD of $\gamma \delta$ T cells in the Peyer's patches, population of $\gamma \delta$ T cells in Peyer's patches, ${ }^{51} \mathrm{Cr}-\gamma \delta$ T cell trafficking into Peyer's patches and diffusive intestinal lymphoid 

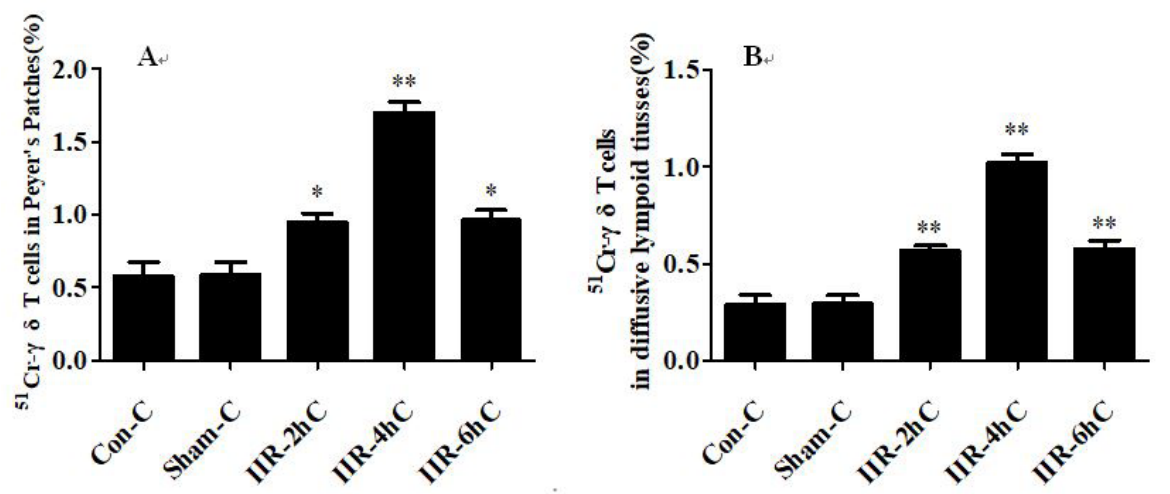

Fig. 5. Changes of in vivo trafficking of ${ }^{51} \mathrm{Cr}$ labeled intestinal $\gamma \delta T$ cells at the different time points after intestinal isochemia-reperfusion (IIR) in rats. A. ${ }^{51} \mathrm{Cr}-\gamma \delta T$ cells in Peyer's patches, $B .{ }^{51} \mathrm{Cr}-\gamma \delta \mathrm{T}$ cells in the diffusive lymphoid tissue of the small intestines (exclude Peyer's patches). $n=4$ in each group. Con-C: Control, Sham-C: Sham-operation, IIR-2hC, $4 h C$ and $6 h C:$ at the $2^{\text {nd }}, 4^{\text {th }}$, and $6^{\text {th }}$ hours after reperfusion. ${ }^{*} P<0.05, * * P<0.01$ compared with control group.

tissues (excluding Peyer's patches) had highly positive correlations to degree of intestinal injury (correlation coefficient $=0.999, \mathrm{P}=0.028$; correlation coefficient $=1.000 ; \mathrm{P}=0.004$, correlation coefficient $=0.998 ; \mathrm{P}=0.040$, correlation coefficient $=0.998 ; \mathrm{P}=0.035$, respectively), TNF- $\alpha$ levels (correlation coefficient $=0.999, \mathrm{P}=0.032$; correlation coefficient $=1.000, P=0.007$; correlation coefficient $=0.998, P=0.036$; correlation coefficient $=0.999, \mathrm{P}=0.031$, respectively) and endotoxin concentration (correlation coefficient $=1.000, \mathrm{P}=0.018$; correlation coefficient $=1.000, P=0.007$; correlation coefficient $=0.997, P=0.045$; correlation coefficient $=0.997, P=0.045$, respectively) in mesenteric lymph after reperfusion.

\section{DISCUSSION}

The intestinal injury severity was different at different time points after reperfusion following complete occlusion of the SMA for $45 \mathrm{~min}$. In this study, the abnormalities in the intestinal mucosa after IIR were obvious including small intestinal epithelial cell degeneration, necrosis, or even sloughing off when compared with the control and sham-operation group. Gut injury was more serious at the $4^{\text {th }}$ hour after reperfusion than that at both the $2^{\text {nd }}$ and the $6^{\text {th }}$ hours after reperfusion according to pathological changes of intestinal mucosa and the Park Chiu Scale for grading intestinal injury (Fig. 1). When the gut barrier is injured, the gut-derived endotoxin may enter into the extraintestinal tissues via mesenteric lymph and produce cytokines that potentiate the development of multiple organ dysfunction syndrome (MODS) (24). Mesenteric lymph is the key conduit for factors leaving the gut leading to organ injury and dysfunction (25). When the gut releases a large amount of inflammatory cytokines, including rapidly produced TNF- $\alpha$, intestinal inflammatory damage occurs (26). Therefore, the different concentration of endotoxin and TNF- $\alpha$ in mesenteric lymph is associated with intestinal injury severity. As shown in Fig. 2, the gut-derived endotoxin concentration and the TNF- $\alpha$ level in mesenteric lymph were significantly increased, which reached the peak value at the $4^{\text {th }}$ hour after reperfusion according to the data and consistent with the severity of intestinal injury.

Evidence has been shown that lymphocytes, particularly $T$ cells are the crucial cells during IIR injury, indicating that $\mathrm{T}$ cells modulate the microvascular and inflammatory responses to IIR (9-11,27). Recent data has 
shown that conventional $\gamma \delta$ T cells do not contribute to acute IIR injury (28). Additionally, zhang et al verified that $\gamma \delta$ T cells but not $\gamma \delta \mathrm{T}$ cells contribute to sepsis-induced white matter injury and motor abnormalities in mice (29). It is still not clear whether $\gamma \delta \mathrm{T}$ cells promote the intestinal injury after reperfusion followed by ischemia. In this study, the results from flow cytometry detection demonstrated that the population of $\gamma \delta$ T cells in Peyer's patches of the small intestine was obviously increased after IIR compared with that in the control and sham-operation group, which was increased by $72 \%, 94 \%, 71 \%$, respectively at the $2^{\text {nd }}, 4^{\text {th }}$, and the $6^{\text {th }}$ hours after reperfusion (Fig. 3). This further study strengthened the evidence that the MOD of $\gamma \delta$ T cells staining in Peyer's patches during the IIR injury was higher than that in the control and sham operation group, in which the MOD at the $4^{\text {th }}$ hour after reperfusion was highest compared with that at both the $2^{\text {nd }}$ and the $6^{\text {th }}$ hours after reperfusion (Fig. 4). It is interesting to note that the distribution of $\gamma \delta$ T cells in Peyer's patches shows some differences among the three time points after IIR, in which $\gamma \delta \mathrm{T}$ cells mainly concentrate in the center of the lymphoid follicle at the $4^{\text {th }}$ hour after reperfusion and scatter on the edge of the lymphatic follicle at both the $2^{\text {nd }}$ and the $6^{\text {th }}$ hour after reperfusion (Fig. 4). Peyer's patches are an important part of gut-associated lymphoid tissues, which are a group of lymphoid follicles composed of $T$ cells and $B$ cells, particularly $\gamma \delta \mathrm{T}$ cells in the small intestinal mucosa (30). $\gamma \delta$ T cells in Peyer's patches participate in the local immuno-inflammatory response of the intestinal tract (31). During the IIR injury, the increased population of $\gamma \delta \mathrm{T}$ cells in the gut was consistent with the intestinal damage severity, which supports that $\gamma \delta \mathrm{T}$ cells participate in the local immunoinflammatory reaction and even cause intestinal damage. However, it is still unclear where these increased $\gamma \delta$ T cells come from, the skin, the genital tract and respiratory tract mucosa or small intestinal mucosa itself?

The mesenteric lymph is considered as a potential pathway by which gut injury leads to other organ or tissue dysfunction (32). The functional integrity of the intestinal mucosal immune system is dependent upon the continual trafficking of lymphocytes including $\gamma \delta \mathrm{T}$ cells between the gut and blood stream (33). Any factors that disrupt normal intestinal lymphocyte traffic could impair local intestinal mucosal immune function (34). In this study, $\gamma \delta \mathrm{T}$ cells in mesenteric lymph labeled with ${ }^{51} \mathrm{Cr}$ and infused into the blood circulation from the femoral vein after reperfusion followed by ischemia, and $1 \mathrm{~h}$ later, the distribution of ${ }^{51} \mathrm{Cr}-\gamma \delta \mathrm{T}$ cells in the gut was observed. The population of ${ }^{51} \mathrm{Cr}-\gamma \delta \mathrm{T}$ cells in Peyer's patches and the diffusive lymphoid tissue of the small intestines (excluding Peyer's patches) was significantly increased at the $2^{\text {nd }}$, $4^{\text {th }}$, and the $6^{\text {th }}$ hour after reperfusion compared with the control and sham-operation group, which reaches a maximum at the 4th hour after reperfusion among the three time points after IIR (Fig. 5). These results show that after the gut reperfusion, a portion of the increased intestinal $\gamma \delta \mathrm{T}$ cells migrates from the gut itself in a manner of tissue-specific homing. The chemokine responsible for efficient trafficking and retention of $\gamma \delta \mathrm{T}$ cells (35) is integrin $\alpha 4 \beta 7$ expressed on the surface of $\gamma \delta \mathrm{T}$ cells, which is integral to guiding the homing of $\gamma \delta \mathrm{T}$ cells to the gut through its interaction with mucosal addressin cell adhesion molecule-1 (MAdCAM-1), which is expressed on high endothelial venules in the small intestines (36). $\alpha 4 \beta 7$ is activated by different chemokines in a ligand-specific manner (35). CCL25 stimulation promotes $\alpha 4 \beta 7$-mediated lymphocyte adhesion to MAdCAM-1, whereas CXCL10 stimulation suppresses their adhesion (35).

Furthermore, Spearman correlation coefficient analyses indicated that the increased population of ${ }^{51} \mathrm{Cr}-\gamma \delta$ T cells in Peyer's patches and the diffusive lymphoid tissues of the small intestines had highly positive correlation to their Park Chiu Scale of the gut injury, which suggests that increased $\gamma \delta$ T cells trafficking into intestinal mucosa may be the promoting agent for intestinal damage during the 
development of IIR injury. Meanwhile, there was a highly positive correlation between the increased population of ${ }^{51} \mathrm{Cr}-\gamma \delta \mathrm{T}$ cells in the small intestinal mucosa and TNF- $\alpha$ activity or endotoxin concentration in mesenteric lymph after IIR, which suggests that the increased $\gamma \delta$ $\mathrm{T}$ cells probably participates in the production of cytokines including TNF- $\alpha$ and even cause the local immune-inflammatory responses of the gut.

According to the above, we may speculate that during the development of IIR injury, the increased population of $\gamma \delta$ T cells migrating across intestinal mucosa might promote the intestinal injury probably through aggravating the local intestinal immuno-inflammatory responses. It should be pointed out that the IIR rat model used in this study was an extreme model of absolute ischemia, which did not represent the relative ischemia seen in traumatic hemorrhage, sepsis or in the poorly perfused organs harvested for transplantation.

\section{ACKNOWLEDGMENTS}

This research was supported by the Open Project Program of the State Key Laboratory of Trauma, Burn and Combined Injury, Army Military Medical University (grant to SKLKF201711) and the Key Project of Science and Technology Development of Nanjing Medical University (grant to 2016NJMUZD050).

\section{AUTHOR CONTRIBUTIONS}

Yang, J, Shen, Y, Wu RQ, and Zhu, H performed experiments. Yang, J, Yang, $\mathrm{H}$ analyzed the data. Jin, Y participated in research design, and Yang, $\mathrm{H}$ wrote the paper. All authors reviewed the manuscript.

\section{CONFLICT OF INTEREST AND DISCLOSURE}

The author declares no competing financial interests exist.

\section{REFERENCES}

1. Matsuo, S, A Chaung, D Liou, et al: Inhibition of ubiquitin-activating enzyme protects against organ injury after intestinal ischemia-reperfusion. Am. J. Physiol. Gastrointest. Liver Physiol. 315 (2018), G283-G292.

2. Kim, JH, J Kim, J Chun, et al: Author Correction: Role of $\mathrm{iRhom} 2$ in intestinal ischemiareperfusion-mediated acute lung injury. Sci. Rep. 8 (2018),7087.

3. Turan, I, HS Ozacmak, VH Ozacmak, et al: Agmatine attenuates intestinal ischemia and reperfusion injury by reducing oxidative stress and inflammatory reaction in rats. Life Sci. 189 (2017), 23-28.

4. Yu, Y, C Klemann, X Feng, et al: Increased inflammatory reaction to intestinal ischemiareperfusion in neonatal versus adult mice. Eur. J. Pediatr. Surg. 25 (2015),46-50.

5. Kalogeris, T, CP Baines, M Krenz, et al: Ischemia/Reperfusion. Compr Physiol. 7 (2016),113-170.

6. Kalogeris, T, CP Baines, M Krenz, et al: Cell biology of ischemia/reperfusion injury. Int. Rev. Cell Mol. Biol. 298 (2012), 229-317.

7. Eltzschig, HK, E Tobias: Ischemia and reperfusion-from mechanism to translation. Nat. Med. 17 (2011), 10.1038/nm.2507.

8. Yang, X, H Bai, Y Wang, et al: Deletion of regulatory $T$ cells supports the development of intestinal ischemia-reperfusion injuries. J. Surg. Res. 184 (2013), 832-837.

9. Yang, H, Y Jin, M Li, et al: Disturbances of mesenteric lymph flow and in vivo intestinal lymphocyte trafficking during early gut injury induced by ischemia-reperfusion in rats. Lymphology 45 (2012), 130-139.

10. Linfert, D, T Chowdhry, H Rabb: Lymphocytes and ischemia-reperfusion injury. Transplant Rev. (Orlando) 23 (2009),1-10.

11. Shigematsu, T, RE Wolf, DN Granger: T- lymphocytes modulate the microvascular and inflammatory responses to intestinal ischemia reperfusion. Microcirculation 9 (2002), 99-109.

12. Edgerton, C, JC Crispín, CM Moratz, et al: IL-17 producing CD4+ T cells mediate accelerated ischemia/reperfusion induced injury in autoimmunity-prone mice. Clin. Immunol. 130 (2009), 313-321.

13. de Oliveira, H, C Penido: $\gamma \delta \mathrm{T}$ lymphocytes coordinate eosinophil influx during allergic responses. Front Pharmacol. 3 (2012), 200.

14. Nielsen, MM, DA Witherden, WL Havran: $\gamma \delta \mathrm{T}$ cells in homeostasis and host defense of epithelial barrier tissues. Nat. Rev. Immunol. 17 (2017), 733-745. 
15. Cruz, MS, A Diamond, A Russell, et al: Human $\gamma \delta$ and $\gamma \delta$ T cells in skin immunity and disease. Front Immunol. 9:1304. doi:10.3389/ fimmu. 2018. 01304.

16. Hayday, AC: $\gamma \delta$ cells: A right time and a right place for a conserved third way of protection. Annu. Rev. Immunol. 18 (2000), 975-1026.

17. Chien, YH, C Meyer, M Bonneville: $\gamma \delta$ T cells: First line of defense and beyond. Annu, Rev, Immunol. 32 (2014), 121-155.

18. Gomes, AQ, DS Martins, B Silva-Santos: Targeting $\gamma \delta \mathrm{T}$ lymphocytes for cancer immunotherapy: From novel mechanistic insight to clinical application. Cancer Res. 70 (2010), 10024-10027.

19. Girardi,M, AC Hayday: Immunosurveillance by $\gamma \delta \mathrm{T}$ cells: focus on the murine system. Chem. Immunol. Allergy 86 (2005), 136-150.

20. Peters, C, D Kabelitz, D Wesch: Regulatory functions of $\gamma \delta$ T cells. Cell. Mol. Life Sci. 75 (2018), 2125-2135.

21. Fleming, C, S Morrissey, Y Cai, et al: $\gamma \delta \mathrm{T}$ cells: unexpected regulators of cancer development and progression. Trends Cancer 3 (2017), 561-570.

22. Yang, H, Y Jin, C Wang, et al: Effects of exogenous vasoactive intestinal peptide on mesenteric lymph pathway during early intestinal ischemia-reperfusion injury in rats. Regul. Pept. 186 (2013), 36-42.

23. Oltean, M, M Olausson: The Chiu/Park scale for grading intestinal ischemia reperfusion: If it ain't broke don't fix it! Inten. Care Med. 36 (2010), 1095.

24. Edrees, WK, LL Lau, IS Young, et al: The effect of lower limb ischemia-reperfusion on intestinal permeability and the systemic inflammatory response. Eur. J. Vasc. Endovasc. Surg. 259 (2003), 330-335.

25. Deitch, EA: Role of the gut lymphatic system in multiple organ failure. Curr. Opin. Crit. Care 7 (2001), 92-98.

26. Zhang, Y, YF Leng, X Xue, et al: Effects of penehycliding hydrochloride in small intestinal damage caused by limb ischemia-reperfusion. World J. Gastroenterol. 17 (2011), 254-259.

27. Yang, DJ, ZX Zhu, HB Fu, et al: Hypertonic saline activates CD4+ and CD8+ T-lymphocytes in the small intestine to alleviate intestinal ischemia-reperfusion injury. Eur. Rev. Med. Pharmacol. Sci. 18 (2014), 3069-3075.
28. Yu, Y, XY Feng, G Vieten, et al: Conventional alpha beta $(\gamma \delta)$ T cells do not contribute to acute intestinal ischemia reperfusion injury in mice. PLoS One 12 (2017), e0181326.

29. Zhang, $\mathrm{X}, \mathrm{E}$ Rocha Ferreira, T Li, et al: $\gamma \delta \mathrm{T}$ cells but not $\gamma \delta \mathrm{T}$ cells contribute to sepsis- induced white matter injury and motor abnormalities in mice. J. Neuroinflammation 14 (2017), 255.

30. Maroilley, T, M Berri, G Lemonnier, et al: Immunome differences between porcine ileal and jejunal Peyer's patches revealed by global transcriptome sequencing of gut associated lymphoid tissues. Sci. Rep. 8 (2018), 9077.

31. Hui, L, Y Dai, Z Guo, et al: Immunoregulation effects of different $\gamma \delta$ T cells and toll-like receptor signaling pathways in neonatal necrotizing enterocolitis. Medicine (Baltimore) 96 (2017), e6077.

32. Kojima, M, JA Gimenes-Junior, TW Chan, et al: Exosomes in postshock mesenteric lymph are key mediators of acute lung injury triggering the macrophage activation via Toll-like receptor 4. FASEB J. 32 (2018), 97-110.

33. Do, J, S Kim, K Keslar, et al: $\gamma \delta$ T cells coexpressing gut homing $\alpha 4 \beta 7$ and $\alpha E$ integrins define a novel subset promoting intestinal inflammation. J. Immunol. 198 (2017), 908-915.

34. Habtezion, A, LP Nguyen, H Hadeiba, et al: Leukocyte trafficking to the small intestine and colon. Gastroenterology 150 (2016), 340-354.

35. Sun, H, J, Liu, Y, Zheng, et al: Distinct chemokine signaling regulates integrin ligand specificity to dictate tissue-specific lymphocyte homing. Developmental Cell 30 (2014), 61-70.

36. Siegers GM. Integral roles for integrins in $\gamma \delta \mathrm{T}$ cell function. Front Immunol. 9 (2018), 521.

\author{
Hui Yang, Ph D \\ Department of Pediatric Gastroenterology \\ Children's Hospital of Nanjing Medical \\ University \\ No.72, Guangzhou Road, Gulou District \\ Nanjing, Jiangsu 210008, P.R. China \\ E-mail: xinghui7325@sina.com \\ Tel: $+\mathbf{8 6 - 2 5 - 8 3 1 1 7 3 6 1}$
}

